Editorial

\title{
Permanent Magnet Synchronous Machines
}

\author{
Sandra Eriksson (D) \\ Department of Engineering Sciences, Uppsala University, Box 534, 75121 Uppsala, Sweden; \\ sandra.eriksson@angstrom.uu.se
}

Received: 2 July 2019; Accepted: 22 July 2019; Published: 23 July 2019

\begin{abstract}
Interest in permanent magnet synchronous machines (PMSMs) is continuously increasing worldwide, especially with the increased use of renewable energy and electrification of transports. This special issue contains the successful invited submissions of fifteen papers to a Special Issue of Energies on the subject area of "Permanent Magnet Synchronous Machines". The focus is on permanent magnet synchronous machines and the electrical systems they are connected to. The presented work represents a wide range of areas. Studies of control systems, both for permanent magnet synchronous machines and for brushless DC motors, are presented and experimentally verified. Design studies of generators for wind power, wave power and hydro power are presented. Finite element method simulations and analytical design methods are used. The presented studies represent several of the different research fields on permanent magnet machines and electric drives.
\end{abstract}

Keywords: permanent magnet synchronous generator; permanent magnet synchronous motor; electric propulsion systems; renewable energy; energy conversion

\section{Introduction}

This special issue contains the successful invited submissions [1-15] to a Special Issue of Energies on the subject area of "Permanent Magnet Synchronous Machines". Interest in permanent magnet (PM) synchronous machines is continuously increasing worldwide. With a growing global energy demand and awareness of climate aspects, electrification is increasing in several areas. Permanent magnet synchronous generators are in demand for wind power, as well as for novel renewable energy technologies such as wave power and tidal power. Another emerging market for permanent magnet machines is as electric motors, mainly for cars but also for heavier road transport, as well as the electrification of ships and aircraft.

This special issue focuses on PM synchronous machines and the electrical systems they are connected to. PM synchronous machines are a multidisciplinary research topic involving research areas such as electromagnetism, mechanical design, thermal management and material issues, as well as economic and environmental aspects. Both theoretical and experimental work and especially the combination of these are important. Recently, an interest in reducing the use of rare earth metals has been raised, and therefore research exploring substitution and reduction of rare earth metals in PM machines is being performed. Topics of interest for research on PM synchronous machines include, but are not limited to:

- Permanent magnet synchronous machine design;

- Modeling of PM machines;

- Innovative designs of PM machines;

- Drive systems for PM motors;

- Electrical systems and control strategies for PM generators;

- Substitution or reduction of rare earth metals in PM machines; 
- Demagnetization risk for PMs in synchronous machines;

- Thermal design and losses;

- Mechanical design;

- PM pilot exciters;

- PM assisted synchronous reluctance machines.

Studies of permanent magnet machines are of more value if they are experimentally verified. However, the effort of experimental verification should not be diminished. Building a prototype and performing measurements is often a time-consuming and difficult task. The majority of the papers presented here include experimental verification of their work.

\section{Research Presented in This Special Issue}

A subject that is currently of high interest is the electrification of the transport sector. This trend can be seen in this special issue as a majority of the papers deals with PM motors with an emphasis on motor control. Five of the fifteen contributions target renewable energy sources $[2-4,9,10]$, whereas the rest are focused on electric motors, with most examining electric vehicles [1,5-8,11-15]. Three of the papers address brushless DC (BLDC) motors [7,11,12]. Six of the contributions present work on motor control, with the work of all six being experimentally verified $[1,6-8,11,15]$. One paper is focused on fault diagnosis for hydropower generators [2]. Almost all PM machines have rare earth metal based magnets made of NdFeB. However, alternatives exist and novel magnets have been heavily researched. Almost all the papers in this special issue are based on NdFeB-magnets, as stated by the authors in references [10-13] or as assumed from the contents in references [1,4-9,14,15]. However, paper [3] investigates a span of magnetic properties, which could fit any magnet material. The generators in reference [2] have electromagnets.

The research presented in this special issue has been divided into two parts presented below: contributions on motor control and contributions on machine design and modeling.

\subsection{Review of the Contributions on Motor Control}

Control of motors commonly requires a speed and position sensor, however, it would be beneficial to not be dependent on a sensor and therefore different types of sensorless control are subject to research. This issue is addressed in reference [1], where a restarting strategy is presented for a back EMF-based sensorless drive for a PM synchronous machine, and the motor voltage is estimated without using the rotor position and speed. The method is experimentally verified and it is concluded that the induced current can be suppressed for various conditions within four to five periods and therefore will not lead to overcurrent fault.

In reference [6] a robust nonlinear predictive current control is presented and compared to conventional predictive current control for a PM synchronous motor. The robust nonlinear predictive current control was experimentally evaluated and compared to the conventional predictive current control under inductance and flux linkage parameter mismatch, and showed superiority on control precision as well as disturbance rejection. Model predictive control is also addressed in reference [8] regarding speed control for a non-salient PM synchronous motor. The developed model predictive control method is compared to traditional control methods both by simulations and experiments. It is concluded that the model predictive control can improve the speed tracking performance of the motor.

Both reference [6] and reference [15] investigate the stability of control methods with regards to machine parameter variations. In reference [15], the stability of deadbeat-direct torque and flux control is investigated with respect to parameter variations for interior PM synchronous motors. The behavior of the controller when the values for inductance and permanent magnet flux linkage varied, was studied using eigenvalue migration as a stability evaluation method. The control method was evaluated both with simulations and experiments, and was compared to current vector control. It was concluded that both control systems show stable operation along a whole driving cycle. 
The studies presented in reference [7] and reference [11] both address the problem with current ripple in BLDC motors. In reference [7] a novel commutation error compensation strategy based on the line voltage difference integral is presented for a sensorless BLDC. A PI controller is designed to compensate commutation errors. Experimental verification of the method shows that the current ripple is effectively reduced. In reference [11], the method of placing an R-C filter before the MOSFET transistor gates was suggested to reduce the current spikes in the start-up and during sudden set point changes. The method was evaluated analytically, using both simulations and experiments. The introduction of the R-C filter reduced current ripple at start-up but increased current ripple at steady state operation. Therefore, a relay was introduced so that the R-C filter only was activated if current spikes were detected. Experimental results showed a 13\% decrease in the current spike amplitude.

\subsection{Review of the Contributions on Machine Design and Modeling}

PM machines can have many different machine topologies. Comparison between different topologies is performed through the finite element method (FEM) simulations in reference [3] and reference [14]. In reference [14], four different machine types for six-phase outer rotor machines are compared. The four topologies studied are: V-shaped interior PM machine, Surface mounted PM machine, PM flux-switching machine and Vernier PM machine. The study concludes that the Vernier PM machine has best operating performance and best fault tolerance capability according to the comparison performed in this study. The study in reference [3] focuses on evaluating a novel PM material by studying a span of values for material properties and their influence on rotor design. The three rotor topologies studied are: surface mounted PM rotor, interior spoke type PM rotor and interior PM rotor with radially magnetized magnets. Machines are optimized for torque production for a fixed PM magnetic energy and demagnetization of PMs is considered. It is concluded that the highest torque is reached for surface mounted PMs with high remanence, whereas the reinforcement obtained with the spoke type topology is needed for low remanence materials. The interior radially magnetized PM topology shows the least sensitivity to demagnetization.

Machine design is the subject of reference [4] and reference [5]. The parametrization of an interior PM machine for dynamic characterization is considered in reference [5]. Two nonlinear models for a two-axis representation of an interior PM machine is presented, one based on the current model and one based on the flux-linkage model. The two models are compared with simulations and experiments. A procedure for fast and reliable parameterization for the flux-linkage model was presented. It is concluded that with the suggested parameterization method, the flux-linkage method is preferable, as the execution time of the simulations was up to $20 \%$ shorter in comparison to the current model.

In reference [4], a simulation method for initial design of linear PM generators run with constant torque angle control was presented. By considering the control strategy already at the design stage, simulations can be simplified substantially. It was shown that the choice of rated current density and shortening of the end winding length were crucial for the design. The choice of rated current density becomes a trade-off between a compact and less expensive generator and a generator with high efficiency and high maximum damping force.

Design and modeling of PM generators for wind turbines is the subject of $[9,10]$ and reference [3]. The reduction of cogging torque for a surface mounted PM generator is addressed in reference [10]. A pre-slot technique is presented, where a stator slot wedge consisting of both magnetic and non-magnetic material is inserted in the front of each slot. FEM simulations confirm that the cogging torque is reduced by up to $47.8 \%$. In reference [9], performance investigation and loss estimation are performed using FEM simulations for a PM generator connected to a non-linear load. A generator with surface mounted magnets mounted in an asymmetrical way is compared to a conventional symmetric surface mounted PM generator. The machine with asymmetrically placed magnets has less harmonics and a smaller cogging torque. Iron loses are investigated and a loss separation technique is used. The rectifier is run with different duty cycles and for different rotational speeds. A close loop control is also tested with a varying duty cycle. A conclusion from the study is the significance of studying 
the machine with FEM simulations. In addition, the efficiency is shown to increase when the closed loop control is used. In reference [13], a simulation method using a novel magnetic reluctance network is proposed for time-efficient interior PM machine design. A node mapping criteria is suggested to accurately take magnetic saturation into account. The method allows for geometrical variations such as varying magnet depth and angle between the magnets. The method is validated by FEM simulations for several v-shaped PM machines and with experiments for a prototype machine, showing good correspondence.

Increasing the field weakening performance for a surface mounted permanent magnet BLDC motor by increasing winding inductance is the subject addressed in reference [12]. A motor design with sub-fractional slot-concentrated winding and unequal tooth geometry is presented with an alternate teeth-wound stator and unequal teeth width. A field weakening controller is presented and an experimental study is performed. The design changes increase the field weakening properties of the machine. However, the field weakening is still not satisfactory for use in electric cars and is lower than for traditional interior PM synchronous motors and induction motors.

A study regarding predictive maintenance and fault analysis in synchronous generators is presented in reference [2]. The method presented is based on electric signature analysis used for condition monitoring on generators in bulk electric systems. The proposed method can detect both mechanical and electrical faults. However, two-pole machines provide an extra challenge, as they have the same mechanical and electrical frequency. The method was proven to be useful by testing the method on an in-service hydropower generator connected to the power system. Two types of faults were detected: an early stage of stator short circuit and a mechanical misalignment. The generators in this study have electromagnets. However, the presented method could also be of interest for PM machines.

\section{Conclusions}

A review of the fifteen papers included in this special issue for "Permanent magnet synchronous machines" has been presented. The research area is of large interest as both renewable energy and the electrification of the transport sector are in focus. The papers have different focus and include studies on design, modeling and control of electrical machines as well as experimental verifications. The papers included in this special issue have contributed to moving the research field of electrical machines and drives forward. The special issue gives an overview of the ongoing research and indicates where the research focus is today within this area.

Acknowledgments: I would like to thank the publisher for inviting me to be the editor for this special issue. I found the edition and selections of papers for this special issue very inspiring and rewarding. I would like to thank the editorial staff and reviewers for their efforts and help during the process.

\section{References}

1. You, Z.-C.; Yang, S.-M. A Restarting Strategy for Back-EMF-Based Sensorless Permanent Magnet Synchronous Machine Drive. Energies 2019, 12, 1818. [CrossRef]

2. Salomon, C.P.; Ferreira, C.; Sant'Ana, W.C.; Lambert-Torres, G.; Borges da Silva, L.E.; Bonaldi, E.L.; de Oliveira, L.E.L.; Torres, B.S. A Study of Fault Diagnosis Based on Electrical Signature Analysis for Synchronous Generators Predictive Maintenance in Bulk Electric Systems. Energies 2019, 12, 1506. [CrossRef]

3. Eklund, P.; Eriksson, S. The Influence of Permanent Magnet Material Properties on Generator Rotor Design. Energies 2019, 12, 1314. [CrossRef]

4. Eriksson, S. Design of Permanent-Magnet Linear Generators with Constant-Torque-Angle Control for Wave Power. Energies 2019, 12, 1312. [CrossRef]

5. Drobnič, K.; Gašparin, L.; Fišer, R. Fast and Accurate Model of Interior Permanent-Magnet Machine for Dynamic Characterization. Energies 2019, 12, 783. [CrossRef]

6. Lyu, M.; Wu, G.; Luo, D.; Rong, F.; Huang, S. Robust Nonlinear Predictive Current Control Techniques for PMSM. Energies 2019, 12, 443. [CrossRef] 
7. Yao, X.; Zhao, J.; Lu, G.; Lin, H.; Wang, J. Commutation Error Compensation Strategy for Sensorless Brushless DC Motors. Energies 2019, 12, 203. [CrossRef]

8. Tang, M.; Zhuang, S. On Speed Control of a Permanent Magnet Synchronous Motor with Current Predictive Compensation. Energies 2019, 12, 65. [CrossRef]

9. Barmpatza, A.C.; Kappatou, J.C. Finite Element Method Investigation and Loss Estimation of a Permanent Magnet Synchronous Generator Feeding a Non-Linear Load. Energies 2018, 11, 3404. [CrossRef]

10. García-Gracia, M.; Jiménez Romero, Á.; Herrero Ciudad, J.; Martín Arroyo, S. Cogging Torque Reduction Based on a New Pre-Slot Technique for a Small Wind Generator. Energies 2018, 11, 3219. [CrossRef]

11. Dahbi, M.; Doubabi, S.; Rachid, A. Current Spikes Minimization Method for Three-Phase Permanent Magnet Brushless DC Motor with Real-Time Implementation. Energies 2018, 11, 3206. [CrossRef]

12. Ustun, O.; Kivanc, O.C.; Senol, S.; Fincan, B. On Field Weakening Performance of a Brushless Direct Current Motor with Higher Winding Inductance: Why Does Design Matter? Energies 2018, 11, 3119. [CrossRef]

13. Caballero, D.; Prieto, B.; Artetxe, G.; Elosegui, I.; Martinez-Iturralde, M. Node Mapping Criterion for Highly Saturated Interior PMSMs Using Magnetic Reluctance Network. Energies 2018, 11, 2294. [CrossRef]

14. Yao, Y.; Liu, C.; Lee, C.H. Quantitative Comparisons of Six-Phase Outer-Rotor Permanent-Magnet Brushless Machines for Electric Vehicles. Energies 2018, 11, 2141. [CrossRef]

15. Lee, J.S. Stability Analysis of Deadbeat-Direct Torque and Flux Control for Permanent Magnet Synchronous Motor Drives with Respect to Parameter Variations. Energies 2018, 11, 2027. [CrossRef]

(C) 2019 by the author. Licensee MDPI, Basel, Switzerland. This article is an open access article distributed under the terms and conditions of the Creative Commons Attribution (CC BY) license (http://creativecommons.org/licenses/by/4.0/). 